\title{
Effects of indigestible carbohydrates in barley on glucose metabolism, appetite and voluntary food intake over $16 \mathrm{~h}$ in healthy adults
}

\author{
Elin V Johansson*, Anne C Nilsson, Elin M Östman and Inger M E Björck
}

\begin{abstract}
Background: Recent knowledge in animals suggests that gut microbial metabolism may affect host metabolism, including appetite regulating hormones. The aim of the present study was to evaluate the potential effects of a whole grain barley kernel product, rich in intrinsic indigestible carbohydrates (dietary fibre and resistant starch), on markers of metabolism and appetite regulation in healthy subjects.
\end{abstract}

Methods: Boiled barley kernels (BK) or white wheat bread (WWB; reference) were provided as late evening meals to 19 young adults in random order using a cross-over design. During subsequent ad libitum standardized breakfast and lunch meals (10.5-16 h), blood was collected for analysis of glucose, plasma insulin, adiponectin, ghrelin, glucose-dependent insulinotropic polypeptide (GIP) and glucagon-like peptide-1 (GLP-1), serum free fatty acids (FFA) and interleukin (IL)-6. In addition, appetite sensations, voluntary energy intake and breath $\mathrm{H}_{2}$ were determined.

Results: BK as evening meal increased plasma GLP-1 at fasting $(P<0.05)$ and during the experimental day $(P<0.01)$ compared with WWB. In addition the BK evening meal decreased fasting serum FFA $(P<0.05)$ and tended to decrease fasting serum IL-6 $(P=0.06)$. At lunch, preceded by BK evening meal, voluntary energy intake was decreased $(P<0.05)$ when compared to WWB evening meal. The BK evening meal decreased incremental blood glucose area $(P<0.01)$, promoted higher breath $\mathrm{H}_{2}(P<0.001)$, maintained adiponectin concentrations $(P<0.05)$ and reduced perceived hunger $(P<0.05)$ during $10.5-16 \mathrm{~h}$ after the meal.

Conclusions: The results indicate that the BK evening meal, facilitate glucose regulation, increase the release of GLP-1, reduce subsequent energy intake while at the same time decreasing hunger over 2 subsequent meals, and reduce fasting FFA the subsequent morning, possibly mediated through gut microbial fermentation of the indigestible carbohydrates.

Keywords: Barley, Dietary fibre, Glucose tolerance, Incretins, GLP-1, Energy intake, Appetite, Colonic fermentation, Metabolic syndrome, Inflammation

\section{Background}

The metabolic syndrome (MetS) represents a cluster of risk factors identifying subjects at high risk of developing type 2 diabetes (T2D) and cardio-vascular disease [1]. The prevalence of obesity and T2D is increasing globally and the World Health Organization estimates in 2012 the number of people suffering from T2D worldwide to

\footnotetext{
* Correspondence: Elin.Johansson@appliednutrition.lth.se

Division of Applied Nutrition and Food Chemistry, Department of Food Technology, Engineering and Nutrition, Lund University, P. O. Box 124, Lund SE-221 00, Sweden
} will increase by two thirds between year 2008 and 2030 [2]. The need for preventive strategies is thus urgent.

Observational studies have shown that higher intake of whole grain (WG) is associated with lower body mass index (BMI) [3-5], improved insulin sensitivity [6], reduced risk of T2D [7] and of premature total and cause-specific death [8]. Several mechanisms have been discussed as mediators of favorable metabolic outcomes following WG intake, e.g. low GI features, presence of dietary fibre (DF) per se and/or the presence of DF associated bioactive 
components [9-12]. It has been hypothesized that dietary factors may affect composition and metabolism of the gut microflora $[13,14]$, and a close connection between the microbial composition and inflammatory status has been observed $[15,16]$. Consequently, metabolic derangement and also obesity has been described as an endotoxemic inflammatory condition triggered by e.g. high fat feeding $[17,18]$. Oligofructose has been shown to increase bifidobacteria in obese mice [19], which was accompanied by improved glucose regulation and a reduced inflammatory tonus [20,21], indicating a prebiotic mechanism. Less is known about possible colonic mediated effects of DF present in WG diets. A relation between WG intake and improved inflammatory status was reported in a cross-sectional study in healthy subjects [22]. In addition, certain WG products, rich in cereal DF and resistant starch (RS) facilitated blood glucose regulation and improved inflammatory tonus in humans in the perspective from a late evening meal to a standardized breakfast, i.e. in the time frame 10 to $12 \mathrm{~h}$ after meal [23]. The metabolic benefits has been proposed to be associated with colonic fermentation of indigestible carbohydrates (DF and RS) [24-26], and an associated increase in systemic levels of glucagon-like peptide-1 (GLP-1) [23]. GLP-1 is increasingly being assigned both anti-diabetic and anti-obesogenic features [27-29], which makes it relevant to perform further studies regarding the possible relation between food derived stimulation of this incretin and effects on metabolic parameters.

The objective of this work was to evaluate the effect of intrinsic indigestible carbohydrates in boiled barley kernels (BK) consumed in the evening on glycaemia, appetite sensations, appetite regulatory hormones and voluntary food intake, at fasting and in the post-prandial phase following two consecutive meals (breakfast and lunch). Variables determined in blood were glucose, insulin, GLP-1, glucosedependent insulinotropic polypeptide (GIP), ghrelin, free fatty acids (FFA), adiponectin and interleukin (IL)-6. In addition breath hydrogen $\left(\mathrm{H}_{2}\right)$ excretion was determined as a marker of colonic fermentation. The breakfast and lunch meals were provided ad libitum, allowing for evaluation of over-night effects on metabolism and appetite regulation in a realistic eating situation. For this purpose, carbohydrate-equivalent meals, consisting of boiled BK or white wheat bread (WWB, reference meal), were provided as evening meals to healthy subjects, using a randomized cross-over design.

\section{Materials and methods}

\section{Subjects}

Nineteen healthy volunteers, 6 men and 13 women aged $24.2 \pm 1.9$ years, with normal body mass indices (BMI) (mean $\pm \mathrm{SD}=22.3 \pm 2.0 \mathrm{~kg} / \mathrm{m}^{2}$ ) participated in the study. The inclusion criteria were age between $20-35$ years, BMI between $18-25 \mathrm{~kg} / \mathrm{m}^{2}$, non-smoker and no known metabolic disorders or food allergies. Approval of the study was given by the Regional Ethical Review Board in Lund, Sweden (Reference 668/2008).

\section{Evening test- and reference meals}

The test- and reference meals were based on 50 g potentially available starch.

$B K$, test meal; One portion (96.8 g) of slightly polished, dried barley kernels (Finax, Helsingborg, Sweden) was boiled for $20 \mathrm{~min}$ in $150 \mathrm{ml}$ water containing $0.25 \mathrm{~g}$ $\mathrm{NaCl}$. All water was absorbed into the kernels. The BK had the appearance of a rice-analogue and was consumed with 250-300 ml water.

WWB, reference meal; The WWB was baked according to a standardized procedure in a home baking machine (Severin model nr. BM 3983; Menu choice, program 2 [white bread, $1000 \mathrm{~g}$, quick (time2:35)]). The bread was made from $540 \mathrm{~g}$ of white wheat flour (Kungsörnen $\mathrm{AB}$, Järna, Sweden), $360 \mathrm{~g}$ water, $4.8 \mathrm{~g}$ dry yeast, $4.8 \mathrm{~g} \mathrm{NaCl}$. After cooling, the crust was removed and the bread was sliced and portions (119.7 g bread) were wrapped in aluminum foil, put into plastic bags and stored in a freezer $\left(-20^{\circ} \mathrm{C}\right)$. At the day of consumption the subjects were instructed to thaw the bread at ambient temperature, still wrapped in aluminium foil and in the plastic bag. The WWB was consumed with 250-300 ml water.

\section{Ad libitum breakfast and ad libitum lunch}

The breakfast consisted of commercial, low fibre, high glycemic index white wheat bread (Dollar Storfranska, Lockarp, Malmö, Sweden), butter (BreGott, Arla Foods, Stockholm, Sweden) and ham. The sandwiches were cut in small pieces $(6.5 \times 6.5 \mathrm{~cm})$, served as doublesandwiches whole or cut diagonally. The subjects were supposed to choose freely the amount ingested. The breakfast was served with $300 \mathrm{ml}$ water.

The lunch consisted of Swedish hash i.e. fried mix of diced potato, meat and onions (Felix Krögarpytt, Procordia Food AB, Eslöv, Sweden). If ketchup (Felix, Procordia Food $A B$, Eslöv, Sweden) was chosen to be consumed with the hash, the subjects was obliged to maintain the amount of ketchup at both lunch situations. Water was served with the lunch $(250 \mathrm{ml})$.

\section{Study design}

The design was randomized cross-over. BK and WWB were included as late evening meals (0930 pm), separated by approximately 1 week. Each evening meal was consumed twice, meaning that the test subject participated at four separated occasions. Fasting measurements were performed at all four visits and postprandial measurements were performed at two of the visits (randomly chosen), one visit after $\mathrm{BK}$ and $\mathrm{WWB}$, respectively. At 
the days for postprandial measurements, test subjects were provided ad libitum intake of breakfast and lunch, and physiological test variables were repeatedly measured during the experimental day. Blood glucose, breath $\mathrm{H}_{2}$, visual analogue scale (VAS) ratings for subjective appetite (hunger, satiety and desire to eat) and samples for measurements of insulin, active ghrelin, total GIP, and active GLP-1 were obtained at fasting and 15, 30, 45, 60, $90,120,180,210,225,240,255,270,300$ and $330 \mathrm{mi}-$ nutes after commencing the breakfast. Samples for IL-6 and adiponectin were collected at 0, 60, 120, 210, 270 and 330 minutes and measurements of FFA were performed at time 0 and $210 \mathrm{~min}$.

\section{Procedure}

The subjects were encouraged to standardize their meal pattern and to maintain their regular eating habits during the experimental period. They were also instructed to avoid alcohol, excessive physical exercise or food rich in DF the day prior to the evening test or reference meals. Furthermore, they should not have taken antibiotics or probiotics during the previous 2 week period. At $0930 \mathrm{pm}$ the evening before each experimental day, the subjects prepared and consumed evening meals in their home. The WWB was distributed as frozen portions; and the uncooked BK were provided in portions ready to cook. The BK meal was prepared according to a detailed written description of the cooking procedure and consumed directly after preparation (see above Evening test and reference meals). After the evening meals, the subjects were fasting until the breakfast was served the subsequent morning at the research department. The subjects arrived to the department at $0745 \mathrm{am}$. An intravenous cannula (BD Venflon, Becton Dickinson) was inserted into an antecubital vein for blood sampling. Fasting (f-) blood samples were collected and appetite and breath $\mathrm{H}_{2}$ registered before the breakfast. Test variables were determined repeatedly in the postprandial period after breakfast and lunch according to time intervals previously stated. The breakfast was consumed at 0800 am and finished within $15 \mathrm{~min}$. Coffee/tea (without milk or sugar) or water $(200 \mathrm{ml})$ were served at $120 \mathrm{~min}$ after the breakfast, each subject keeping the same drink throughout the study. The lunch was served $210 \mathrm{~min}$ after commencing the breakfast. The amounts of breakfast and lunch consumed were registered. During the experimental days $(5.5 \mathrm{~h})$ the subjects were told to maintain a constant, low physical activity, preferably reading or similar.

\section{Analysis of nutrient composition in evening meals, breakfast and lunch}

The test- and reference meals were analysed with respect to total starch [30], available starch [31], RS [32], and DF [33]. Information regarding content of starch and DF in evening test- and reference meals is provided in Table 1. Prior to analysis of total- and available starch, and DF the products were air dried and milled. RS was analysed on products as eaten. Available starch in the BK meal was calculated by subtracting RS from total starch, whereas potentially available starch content in the reference WWB and the commercial white wheat breakfast bread was analysed according to Holm et. al [31].

The nutritional composition of the breakfast and lunch meals is displayed in Table 2. Prior to analysis, the breakfast sandwiches were prepared as eaten and then cut into small pieces and freeze dried. The lunch (hash) was prepared according to instructions and then mixed with addition of water into a paste, followed by freeze drying. Freeze dried samples were ground in a mortar prior to analysis. Samples were analysed for carbohydrates (available starch) [31], protein and fat. Crude protein content was determined using an elemental analyzer (FlashEA 1112, Thermo Fisher Scientific Inc, Waltham, MA, USA). Fat content was measured gravimetrically using the Schmid-Bondzynski-Ratzlaff (SBR) method.

\section{Analysis of physiological variables}

Finger-prick capillary blood samples were taken for determination of blood glucose (HemoCue ${ }^{\circledR} \mathrm{B}$-glucose,

Table 1 Composition of the evening test and reference meals ${ }^{1}$ ( $\%$ dry matter and $\mathrm{g} /$ serving, respectively)

\begin{tabular}{|c|c|c|c|c|c|c|c|c|}
\hline Meals & Portion weight & Total starch & $\mathrm{RS}$ & Available starch & Insoluble DF & Soluble DF & Total DF & $\mathrm{RS}+\mathrm{DF}$ \\
\hline & \multicolumn{8}{|c|}{$\%$ dry matter } \\
\hline $\mathrm{BK}^{2}$ & - & 68.79 & 11.6 & 57.23 & 8.11 & 5.80 & 13.9 & 25.5 \\
\hline \multirow[t]{2}{*}{ WWB } & - & 81.09 & 1.85 & 79.24 & 4.03 & 1.16 & 5.19 & 7.04 \\
\hline & \multicolumn{8}{|c|}{ g/serving } \\
\hline $\mathrm{BK}^{2}$ & $96.8^{3}$ & 60.10 & 10.1 & 50 & 7.09 & 5.06 & 12.2 & 22.3 \\
\hline WWB & 119.7 & 51.34 & 1.17 & $50^{4}$ & 2.29 & 0.66 & 2.95 & 4.12 \\
\hline
\end{tabular}

${ }^{1}$ Available starch calculated by difference between total starch and RS. Values of total and available starch are based on means of 2 replications, RS means of 6 replications, DF means of 3 replications. BK, barley kernel; DF, dietary fibre; RS, resistant starch; WWB, white wheat bread.

2 Analyzed as eaten.

${ }^{3}$ Portion size is based on raw barley kernels.

${ }^{4}$ Analyzed according to Holm et. al (1986) [31]. 
Table 2 Nutritional composition of the breakfast and lunch ${ }^{1}$

\begin{tabular}{|c|c|c|c|c|}
\hline & Carbohydrates $^{2}$ & Protein & Fat & Energy content \\
\hline & \multicolumn{3}{|c|}{$\%$ dry matter } & kcal \\
\hline Breakfast & 62.6 & 11.9 & 13.6 & 59.8 /sandwich \\
\hline Lunch & 38.5 & 13.9 & 27.5 & $234 / 100 \mathrm{~g}$ \\
\hline Ketchup ${ }^{3}$ & - & - & - & $85 / 100 \mathrm{~g}$ \\
\hline
\end{tabular}

${ }^{1}$ The breakfast consisted of commercial white wheat bread with butter and ham and the lunch consisted of Swedish hash, composed of a mix of fried diced potato, meat and onion with the voluntary addition of ketchup. Values of carbohydrate and fat are based on means of 2 replications, protein means of 4 replications and fat means of 2 replications.

${ }^{2}$ Analyzed as available starch according to Holm et. al (1986) [31].

${ }^{3}$ Values obtained from the manufacturer.

HemoCue AB, Ängelholm, Sweden). Venous blood was collected for measurement of serum (s) FFA and s-IL-6, and plasma (p) adiponectin, p-insulin, p-ghrelin, p-GIP and $\mathrm{p}-\mathrm{GLP}-1$.

Milliplex $^{\text {Tix }}$ MAP (HMH-34K Milliplex ${ }^{\text {Tw }}$ MAP, Millipore, St.Charles, USA) analyses were performed for simultaneous measurement of insulin, active ghrelin, total GIP, and active GLP-1. Blood collecting tubes for analysis with Milliplex ${ }^{\mathrm{Tn}}$ MAP were added with an inhibition cocktail consisting of DPPIV-inhibitor (10 $\mu \mathrm{l} / \mathrm{ml}$ blood) (Millipore, St Charles, USA) and Pefablock SC (1 mg/ml blood) (Roche Diagnostics, Mannheim, Germany) prior to blood sampling. Tubes containing inhibition cocktail were kept cold for maximum 6 days until blood sampling. After blood collection the tubes intended for Milliplex ${ }^{\text {tM }}$ MAP analyses were centrifuged within 30 minutes at $1000 \times \mathrm{g}$ for 10 minutes in $4^{\circ} \mathrm{C}$. The plasma was removed and immediately stored $\left(-20^{\circ} \mathrm{C}\right)$ in Eppendorf-tubes until analysis. The blood samples were analysed using immunoassays on the surface of fluorescently labelled microsphere beads and read on the Luminex 200 instrument (Luminex Corporation, USA). Milliplex $^{\text {mit }}$ Analyst v.3.4 (VigeneTech Inc., Carlisle, USA) was used for the evaluation of the results.

Plasma and serum for analysis of FFA, IL-6 and adiponectin were allowed to clot in ambient temperature (serum) or kept on ice and centrifuged within $30 \mathrm{mi}-$ nutes (plasma). Samples were separated $(3500 \mathrm{rpm}$ for $10 \mathrm{~min}$ in $\left.4^{\circ} \mathrm{C}\right)$ and stored in a freezer $\left(-20^{\circ} \mathrm{C}\right)$ until analysed. FFA concentrations were determined with an enzymatic colorimetric method (NEFA C, ACS-ACOD method, WAKO Chemicals GMbH, Germany). IL-6 was determined with a high sensitivity solid-phase immunoassay kit (R\&D Systems Inc, Minneapolis, USA). Adiponectin concentrations were measured with a solid phase 2-site enzyme immunoassay kit (Mercodia Adiponectin ELISA, Mercodia, Uppsala, Sweden). Hydrogen in expired air was measured as an indicator of colonic fermentation using an EC 60 or Gastro+ (Bedfont EC60 Gastrolyzer, Rochester, England).

\section{Calculations and statistical methods}

Data are expressed as means \pm SEM. The incremental area- and area under the curve (iAUC and AUC, respectively) was calculated for each subject and test meal, using the trapezoid model. iAUC or AUC were used in the statistical evaluation of results regarding blood glucose, insulin, GLP-1, GIP, ghrelin and appetite. Incremental peak (iPeak) concentrations were calculated for glucose and insulin as individual maximum postprandial increase from baseline. For calculation of incremental responses, the specific fasting value at the day for postprandial measurements was used. GraphPad Prism (version 4 and 5, GraphPad Software, San Diego, CA, USA) was used for graph plotting and calculation of AUC. Significant differences in test variables after the different test meals were assessed with ANOVA (general linear model), in MINITAB Statistical Software (release 14; Minitab, Minitab Inc, State College, PA). In the cases of unevenly distributed residuals (tested with Anderson-Darling and considered unevenly distributed when $P<0.05$ ), Box Cox transformation were performed on the data prior to the ANOVA. Differences between the products at different time points were evaluated using a mixed model (PROC MIXED in SAS release 9.2; SAS Institute Inc, Cary, NC) with repeated measures and an autoregressive covariance structure. Randomization of the test products were performed in MINITAB Statistical Software (release 14; Minitab, Minitab Inc, State College, PA). If the value from a test subject were missing for one of the products, the test subject was excluded from that specific calculation.

For breath hydrogen where the variation in the concentration scarcely changed over time, a weighted mean were produced by calculating a mean for equal time intervals ( 1 mean per hour) over the test period, and then a mean for the different hours were calculated and used in statistical analysis. One subject failed to follow instructions at voluntary food intake and data from this variable and subject is therefore excluded from the statistical analysis $(n=18)$. Due to analytical difficulties two subject are withdrawn from blood glucose calculations $(n=17)$. The glucose profile $\left(G^{2}\right)$ is calculated as the time (min) during which the blood glucose are above fasting concentration divided with the squared incremental peak value $(\mathrm{mM})$ of blood glucose for each test subject and test meal. In the cases where the blood glucose concentration remained above fasting for the entire $210 \mathrm{~min}$, the duration value was set to $210 \mathrm{~min} . \mathrm{GP}^{2}$ is used as a measure of the course of glycaemia including also characteristics in the late postprandial phase, high values are considered beneficial [34]. $P$-values $<0.05$ were considered statistically significant. 
Table 3 Physiological responses, breath $\mathrm{H}_{2}$ and subjective appetite scores at fasting, $\mathbf{1 0 . 5} \mathrm{h}$ after evening test- or reference meal $^{1}$

\begin{tabular}{|c|c|c|c|}
\hline Test variables & WWB & BK & $\%^{2}$ \\
\hline Glucose $(\mathrm{mmol} / \mathrm{L})$ & $5.2 \pm 0.1$ & $5.3 \pm 0.1^{3}$ & 2 \\
\hline Insulin (pg/mL) & $607 \pm 78$ & $600 \pm 58$ & -1 \\
\hline GLP-1 $(p g / m L)$ & $57.1 \pm 8.2$ & $68.7 \pm 9.1 *$ & 20 \\
\hline $\mathrm{GIP}(p g / m L)$ & $26.5 \pm 2.1$ & $29.5 \pm 2.4$ & 11 \\
\hline Ghrelin (pg/mL) & $108 \pm 12.7$ & $91.1 \pm 9.3^{3}$ & -16 \\
\hline FFA $(m m o / / L)$ & $0.38 \pm 0.03$ & $0.31 \pm 0.03 *$ & -18 \\
\hline IL-6 (pg/mL) & $0.60 \pm 0.07$ & $0.49 \pm 0.03^{4}$ & -18 \\
\hline Adiponectin $(\mu \mathrm{g} / \mathrm{mL})$ & $9.3 \pm 0.5$ & $9.2 \pm 0.5$ & -1 \\
\hline $\mathrm{H}_{2}(p p m)$ & $16.5 \pm 2.0$ & $24.7 \pm 2.2 * *$ & 50 \\
\hline Satiety $(m m)$ & $18.8 \pm 2.7$ & $22.8 \pm 3.1$ & 21 \\
\hline Hunger (mm) & $60.3 \pm 3.4$ & $61.8 \pm 4.3$ & 2 \\
\hline
\end{tabular}

${ }^{1}$ Values are means \pm SEM. ${ }^{*}$ Different from WWB $P<0.05 ; * * P<0.01$. BK, barley kernel; f-, fasting-; GIP, glucose-dependent insulinotropic polypeptide; GLP-1, glucagon-like peptide- $1 ; \mathrm{H}_{2}$, breath hydrogen; $W W B$, white wheat bread.

${ }^{2}$ The percentage change is calculated as the difference from the WWB to the BK.

${ }^{3} P=0.07$

${ }^{4} P=0.06$

\section{Results}

Breath $\mathrm{H}_{2}$

The f-breath $\mathrm{H}_{2}$ excretion $(P<0.01)$ and the mean breath $\mathrm{H}_{2}$ excretion during the experimental day (0-330 min, $P<0.001)$ was significantly elevated after $\mathrm{BK}$ as a late evening meal compared to the WWB reference meal (Table 3-4, Figure 1).

\section{Voluntary energy intake at breakfast and lunch}

Ad libitum energy intake at breakfast was $400 \mathrm{kcal}$ and $415 \mathrm{kcal}$ following BK and WWB evening meal, respectively, with no significant difference depending on the previous evening meal (Table 4). When given $\mathrm{BK}$ as a late evening meal the test subjects significantly reduced their energy intake at lunch by $12 \%$, compared to energy intake at lunch after the WWB evening meal $(P<0.05)$ (Table 4$)$. The cumulative energy intake over breakfast and lunch tended to be lower after boiled $\mathrm{BK}$ as compared to after the WWB evening meal $(-9 \%)(P=0.07)$

\section{Glucose and insulin}

No differences were seen in f-glucose- or f-insulin concentrations depending on previous evening meals (Table 3). The BK evening meal reduced the glucose iAUC during the course of the entire experimental day (0-330 min, $P<0.01$ ), compared with the WWB evening meal. After breakfast there was also a reduced glucose iPeak following BK as an evening meal $(P<0.001)$, as compared to WWB (Figure 2). In addition, the $\mathrm{GP}^{2}$ value was higher after breakfast post the evening meal with BK $(P<0.05)$ (Table 5). No significant differences

Table 4 Appetite sensations, breath $\mathrm{H}_{2}$ and energy intake after breakfast and lunch, following evening test- or reference meal $^{1}$

\begin{tabular}{|c|c|c|c|}
\hline Test variables & WWB & BK & $\%^{2}$ \\
\hline \multicolumn{4}{|l|}{ Breakfast (0-210 min) } \\
\hline Energy intake, breakfast (kcal) & $415 \pm 38.0$ & $400 \pm 30.7$ & -4 \\
\hline Hunger, AUC 0-120 min (min.mm) & $3330 \pm 343$ & $2960 \pm 372$ & -11 \\
\hline Hunger, AUC 120-210 min (min.mm) & $4750 \pm 380$ & $4090 \pm 395^{*}$ & -14 \\
\hline Satiety, AUC 0-120 min (min.mm) & $6130 \pm 384$ & $6510 \pm 365$ & 6 \\
\hline Satiety, AUC 120-210 min (min.mm) & $2780 \pm 425$ & $3180 \pm 342$ & 14 \\
\hline Desire to eat, AUC 0-120 min (min.mm) & $3600 \pm 413$ & $3310 \pm 488$ & -8 \\
\hline Desire to eat, AUC 120-210 $\mathrm{min}(\mathrm{min} \cdot \mathrm{mm})$ & $5000 \pm 433$ & $4530 \pm 477$ & -10 \\
\hline $\mathrm{H}_{2}$, mean 0-120 $\min (\mathrm{ppm})$ & $11 \pm 2.1$ & $33 \pm 4.4^{* * *}$ & 200 \\
\hline \multicolumn{4}{|l|}{ Lunch $(210-330 \mathrm{~min})$} \\
\hline Energy intake, lunch (kcal) & $804 \pm 98.4$ & $709 \pm 74.0^{*}$ & -12 \\
\hline $\mathrm{H}_{2}$, mean 210-330 min (ppm) & $7.9 \pm 1.3$ & $29 \pm 4.7^{* * *}$ & 267 \\
\hline \multicolumn{4}{|l|}{ Breakfast + Lunch $(0-330 \mathrm{~min})$} \\
\hline Energy intake, cumulative (kcal) & $1220 \pm 130$ & $1110 \pm 93.2^{3}$ & -9 \\
\hline Hunger, AUC 0-330 $\min (\min \cdot \mathrm{mm})$ & $10800 \pm 892$ & $9510 \pm 997^{*}$ & -12 \\
\hline Satiety, AUC 0-330 $\min (\mathrm{min} \cdot \mathrm{mm})$ & $15810 \pm 1060$ & $16540 \pm 917$ & 5 \\
\hline Desire to eat, AUC 0-330 $\min (\mathrm{min} \cdot \mathrm{mm})$ & $11700 \pm 1140$ & $10800 \pm 1220$ & -8 \\
\hline $\mathrm{H}_{2}$, mean 0-330 $\min (\mathrm{ppm})$ & $8.8 \pm 1.5$ & $31 \pm 4.4^{* * *}$ & 248 \\
\hline
\end{tabular}

${ }^{1}$ Values are means \pm SEM. ${ }^{*}$ Different from WWB $P<0.05 ;{ }^{* * *} P<0.001$. AUC, area under curve; BK, barley kernel; $\mathrm{H}_{2}$, breath hydrogen; WWB, white wheat bread.

2 The percentage change is calculated as the difference from the WWB to the BK.

${ }^{3} P=0.07$. 


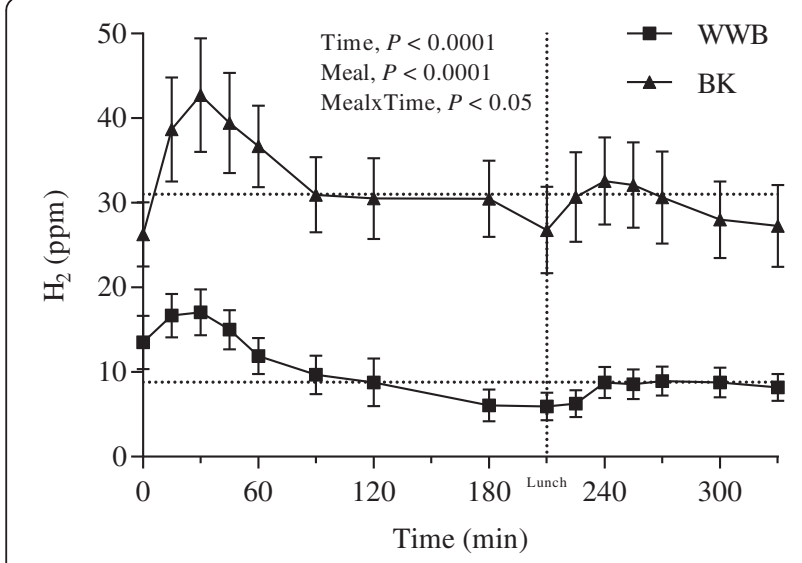

Figure 1 Breath $\mathrm{H}_{2}$ excretion during the experimental day. Mean postprandial $\mathrm{H}_{2}$ excretion 10.5-16 h post ingestion of evening meals with BK or WWB respectively. Values are means \pm SEM. Dotted lines at the $y$-axes indicate weighted mean calculated for WWB (8.8 ppm) and BK (31 ppm), respectively. BK, barley kernel; $\mathrm{H}_{2}$, breath hydrogen; WWB, white wheat bread.

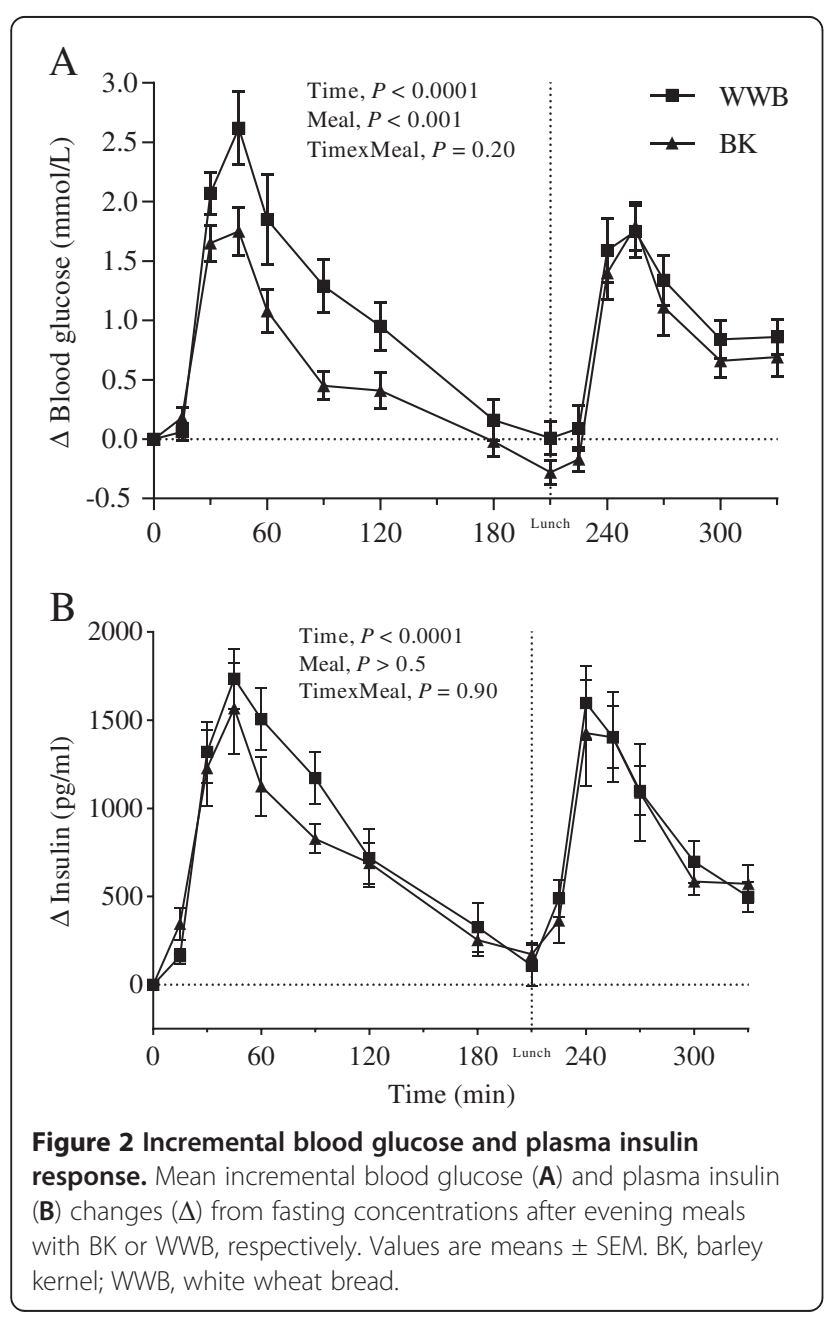

were observed in the post-prandial response of insulin depending on evening meals (Figure 2, Table 5).

\section{FFA}

The BK evening meal generated lower concentrations of circulating f-FFA compared to the WWB $(P<0.05)$ (Table 3). No significant differences were observed prior to lunch (210 $\mathrm{min}$ ) in FFA depending on the preceding evening meal (BK $0.20 \pm 0.03$; WWB $0.21 \pm 0.04 \mathrm{mmol} / \mathrm{L}$ ).

\section{Incretin hormones and ghrelin}

The GLP-1 concentrations were significantly increased at fasting $(P<0.05$, Table 3$)$ and during the whole experimental period (AUC 0-330 min, $P<0.01$, Figure 3, Table 6), after BK as compared to WWB evening meal. Significantly raised concentrations of GIP were observed in the postprandial period 60-120 min (AUC) after breakfast post BK evening meal $(12.8 \pm 1.0 \mathrm{pg} \cdot \mathrm{min} / \mathrm{L})$ as compared to after WWB evening meal $(10.7 \pm 0.9 \mathrm{pg} \cdot \mathrm{min} / \mathrm{L})$ $(P<0.05)$. At fasting a trend $(P=0.07)$ was observed toward decreased concentration of plasma ghrelin after BK as compared to WWB evening meal. No significant differences were detected in the post-prandial ghrelin response (Table 6, Figure 4).

\section{Inflammatory variables}

There was a tendency towards decreased f-IL- 6 concentrations after BK evening meal $(P=0.06)$ (Table 3$)$. The postprandial concentration of IL-6 is shown in Figure 5. There were no significant differences in the fasting state of adiponectin depending on the previous evening meal. However, a less pronounced decrease in plasma adiponectin concentrations from fasting state $(0-330 \mathrm{~min})$ was observed after BK as an evening meal $(-1.4 \%)$ compared to after WWB evening meal $(-7.9 \%)(P<0.05)$ (Figure 5$)$.

\section{Subjective appetite ratings}

Postprandial results for subjective appetite ratings are presented in Figure 6 and Table 4. No significant differences were measured in subjective appetite ratings in the fasting state depending on the previous evening meal (Table 3). There was a lower feeling of hunger at breakfast and lunch (AUC 0-330 min) after BK evening meal, as compared to the WWB evening meal $(P<0.05)$. Also, the BK evening meal generated attenuated feeling of hunger in the late postprandial period after breakfast as compared to the WWB (AUC 120-210 min) $(P<0.05)$.

\section{Discussion}

The purpose of the present study was to examine the metabolic effects of intrinsic fermentable carbohydrates in boiled barley kernels in an over-night perspective. In comparison to previous studies [23,35], the experimental design is novel in that the experimental sampling period 
Table 5 Results for blood glucose and plasma insulin after breakfast and lunch, following evening test- or reference meal $^{1}$

\begin{tabular}{|c|c|c|c|}
\hline Test variables & WWB & BK & $\%^{2}$ \\
\hline \multicolumn{4}{|l|}{ Breakfast (0-120 min) } \\
\hline Glucose, iPeak (mmol/L) & $3.0 \pm 0.3$ & $2.0 \pm 0.2^{* * *}$ & -33 \\
\hline Glucose, iAUC 0-120 $\mathrm{min}(\mathrm{mmol} \cdot \mathrm{min} / \mathrm{L})$ & $168 \pm 21.6$ & $98.7 \pm 10.3^{* * *}$ & -41 \\
\hline Glucose, GP $\left(\mathrm{min} / \mathrm{mmol}^{2}\right)$ & $24.6 \pm 4.1$ & $39.0 \pm 4.8^{*}$ & 59 \\
\hline Insulin, iPeak (pg/mL) & $2270 \pm 168$ & $1710 \pm 244$ & -16 \\
\hline Insulin, iAUC 0-120 $\mathrm{min}(\mathrm{pg} \cdot \mathrm{min} / \mathrm{mL})$ & $125100 \pm 10650$ & $106700 \pm 13210$ & -15 \\
\hline \multicolumn{4}{|l|}{ Lunch (210-330 $\mathrm{min})$} \\
\hline Glucose, iPeak (mmol/L) & $2.2 \pm 0.2$ & $2.0 \pm 0.2$ & -7 \\
\hline Glucose, iAUC 210-330 $\mathrm{min}(\mathrm{mmo} / \mathrm{min} / \mathrm{L})$ & $126 \pm 14.8$ & $107 \pm 12.8$ & -15 \\
\hline Insulin, iPeak (pg/mL) & $1790 \pm 223$ & $1740 \pm 282$ & -3 \\
\hline Insulin, iAUC 210-330 $\mathrm{min}(\mathrm{pg} \cdot \mathrm{min} / \mathrm{mL})$ & $103400 \pm 9260$ & $100200 \pm 17770$ & -3 \\
\hline \multicolumn{4}{|l|}{ Breakfast + Lunch (0-330 min) } \\
\hline Insulin, iAUC (pg.min/mL) & $276300 \pm 25620$ & $241300 \pm 32810$ & -13 \\
\hline Glucose, iAUC (mmol.min/L) & $341 \pm 36.3$ & $227 \pm 23.8^{* *}$ & -34 \\
\hline
\end{tabular}

${ }^{1}$ Values are means \pm SEM. ${ }^{*}$ Different from WWB $P<0.05 ;{ }^{* *} P<0.01 ; * * P<0.001$. BK, barley kernel; GP ${ }^{2}$, glucose profile; iAUC, incremental area under curve; iPeak, incremental peak; WWB, white wheat bread.

2 The percentage change is calculated as the difference from the WWB to the BK.

is significantly extended, covering a period ranging from 10.5-16 $\mathrm{h}$ after ingestion of test and reference evening meal. Further the present study aimed to investigate the influence of evening meals on metabolic test variables, appetite, and voluntary energy intake following ad libitum breakfast- and lunch meals; that is in a more realistic eating situation than studies with standardized meal size.

Previous studies have revealed that dietary supplementation of inulin and oligofructan during two weeks [28], or consumption of other specific indigestible carbohydrates, e.g. present in $\mathrm{BK}$, as a single late evening meal $[23,36]$, decrease the glucose response and increase gut

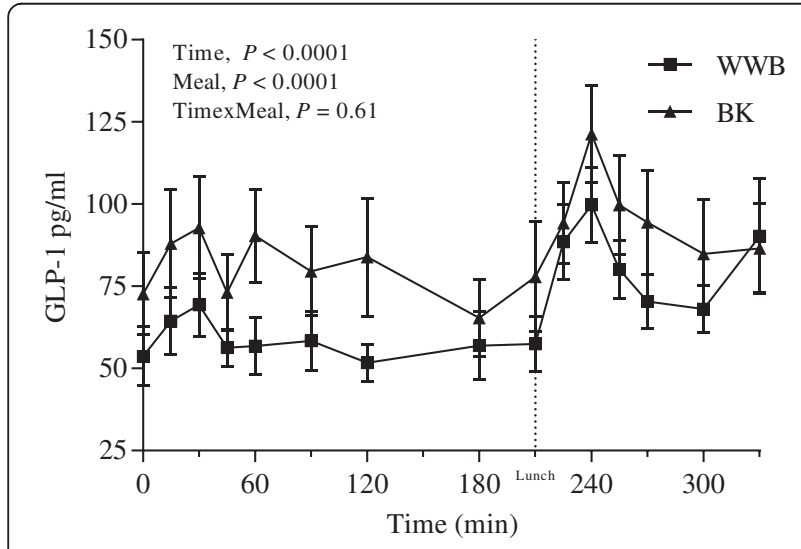

Figure 3 GLP-1 response. Mean concentration of plasma GLP-1 during the experimental day following evening meals with BK or WWB, respectively. Values are means \pm SEM. BK, barley kernel; GLP-1, glucagone-like peptide-1; WWB, white wheat bread. microbial activity (as determined by breath $\mathrm{H}_{2}$ and/or plasma short chain fatty acids (SCFA)) at the following breakfast meal in healthy humans. In accordance with previous findings, the present study revealed decreased glucose response after breakfast following $\mathrm{BK}$ as an evening meal compared to WWB, and increased gut microbial fermentation, as indicated by elevated breath $\mathrm{H}_{2}$ concentrations. As a novel finding, the $\mathrm{BK}$ evening meal decreased glucose iAUC during the course of the entire experimental day (0-330 $\mathrm{min})$, and increased $\mathrm{GP}^{2}$ after breakfast, all indicative of smoother postprandial glucose excursion. In this context it must be noted that in contrast to the standardized meal size previously used, glucose measurements in the present study were conducted after ad libitum food intake (standardized in quality). At breakfast there was only a minor (4\%, non-significant) decrease in energy intake after BK. It is therefore highly unlikely that the differences seen in metabolic variables after breakfast could be explained by differences in energy intake at breakfast. However, the glucose responses at lunch following the BK evening meal may, at least to a minor degree, have been affected by the reduced caloric intake at lunch.

It has been hypothesized that modulation of gut microbiota by oligofructans, may interfere beneficially with host metabolism. Thus, dietary supplementation with oligofructose for 14 weeks decreased glucose AUC and voluntary energy intake, as well as reduced inflammatory tonus in mice models [21]. Studies in rodents have further shown that oligofructose feeding during 4-5 weeks may promote epithelial L-cell differentiation 
Table 6 Plasma GLP-1, GIP and ghrelin response after breakfast and lunch, following evening test- or reference meal ${ }^{1}$

\begin{tabular}{|c|c|c|c|}
\hline Test variables & WWB & BK & $\%^{2}$ \\
\hline \multicolumn{4}{|l|}{ Breakfast (0-120 min) } \\
\hline GLP-1, AUC (pg.min/ml) & $7684 \pm 886$ & $11010 \pm 1671^{* *}$ & 43 \\
\hline GIP, AUC (pg.min/ml) & $18200 \pm 1466$ & $21160 \pm 1524$ & 16 \\
\hline Ghrelin, AUC (pg.min/ml) & $8393 \pm 1077$ & $7351 \pm 901$ & -12 \\
\hline \multicolumn{4}{|l|}{ Lunch (210-330 min) } \\
\hline GLP-1, AUC $(p g \cdot m i n / m l)$ & $10040 \pm 1171$ & $12500 \pm 1757^{*}$ & 25 \\
\hline GIP, AUC (pg.min/ml) & $33300 \pm 3451$ & $29140 \pm 2164$ & -12 \\
\hline Ghrelin, AUC (pg.min/ml) & $10370 \pm 1536$ & $9999 \pm 1143$ & -4 \\
\hline \multicolumn{4}{|c|}{ Breakfast + Lunch $(0-330 \mathrm{~min})$} \\
\hline GLP-1, AUC $(p g \cdot m i n / m l)$ & $22960 \pm 2636$ & $30670 \pm 4310^{* *}$ & 34 \\
\hline $\mathrm{GIP}, \mathrm{AUC}(\mathrm{pg} \cdot \mathrm{min} / \mathrm{ml})$ & $62910 \pm 5354$ & $62590 \pm 4646$ & -0.5 \\
\hline Ghrelin, AUC (pg.min/ml) & $28080 \pm 3672$ & $25850 \pm 3016$ & -8 \\
\hline
\end{tabular}

${ }^{1}$ Values are means \pm SEM. ${ }^{*}$ Different from WWB $P<0.05$; ${ }^{* *} P<0.01$. AUC, area under curve; BK, barley kernel; GIP, glucose-dependent insulinotropic polypeptide; GLP-1, glucagon-like peptide-1; WWB, white wheat bread.

${ }^{2}$ The percentage change is calculated as the difference from the WWB to the BK.

in the gut, contributing to higher GLP-1 production $[20,37]$. It has been demonstrated that SCFA produced by bacterial fermentation may trigger signaling cascades through acting on SCFA receptors on L-cells (in vitro model), resulting in increased release of gut peptides such as GLP-1 and Peptide YY (PYY) [38]. Fructan supplementation during two weeks was also reported to reduce glucose response, reduce feeling of hunger and increase GLP-1 concentration in response to an ad libitum meal in humans [28]. Less is known about the gut mediated effects of intrinsic indigestible carbohydrates in food, e.g. boiled barley kernels, on glycaemia, gut fermentation, and appetite regulation, and to the authors' knowledge, data from human studies are scarce. Nilsson et al. (2008) found inverse correlations between glucose iAUC and breath $\mathrm{H}_{2}$, supporting a link between colonic fermentation and glucose regulation [23]. A particularly interesting observation in the present study is a $34 \%$ increase in plasma concentration of GLP-1 in the morning (0-330 $\mathrm{min}$ ) after the BK evening meal, compared to the evening meal with WWB. In addition, in the time period 60-120 min after breakfast also GIP concentrations (AUC) were increased after BK, which is in accordance with previous findings in our research group [23]. Both GLP-1 and GIP have implications in glucose homeostasis, and in addition GLP-1 is considered as a modulator of appetite regulation. Both glucose intolerance and obesity seems to be related to decreased levels of GLP-1, independently of one another [27]. In the present study, the BK evening meal decreased the feeling of hunger during the whole experimental day, as compared to the evening WWB, and reduced voluntary energy intake (-12\%) at lunch. Previously it has been found that intravenous infusions of GLP-1 (50 pmol/ $\mathrm{kg} \cdot \mathrm{h})$ during $4 \mathrm{~h}$ reduced voluntary energy intake by $12 \%$ at a subsequent lunch meal, as compared to saline in young healthy men [39]. The results in the present study are thus in accordance with previous studies showing that GLP-1 reduce food intake and increase satiety in both lean and obese subjects [40]. Although not significant, there was a trend $(P=0.07)$ to reduced fasting levels of ghrelin after the BK evening meal by $16 \%$ and there was a, non-significant, $10 \%$ reduction of ghrelin in the late post-prandial phase prior to lunch (AUC 120-210 min) as compared to after WWB. Intravenous administration during $4 \mathrm{~h}$ of the orexigenic hormone ghrelin, demonstrates increased food intake in healthy subjects at a subsequent meal [41]. A connection has been proposed between colonic fermentation and reduced concentrations of serum ghrelin in healthy subjects, $6 \mathrm{~h}$ after ingestion of

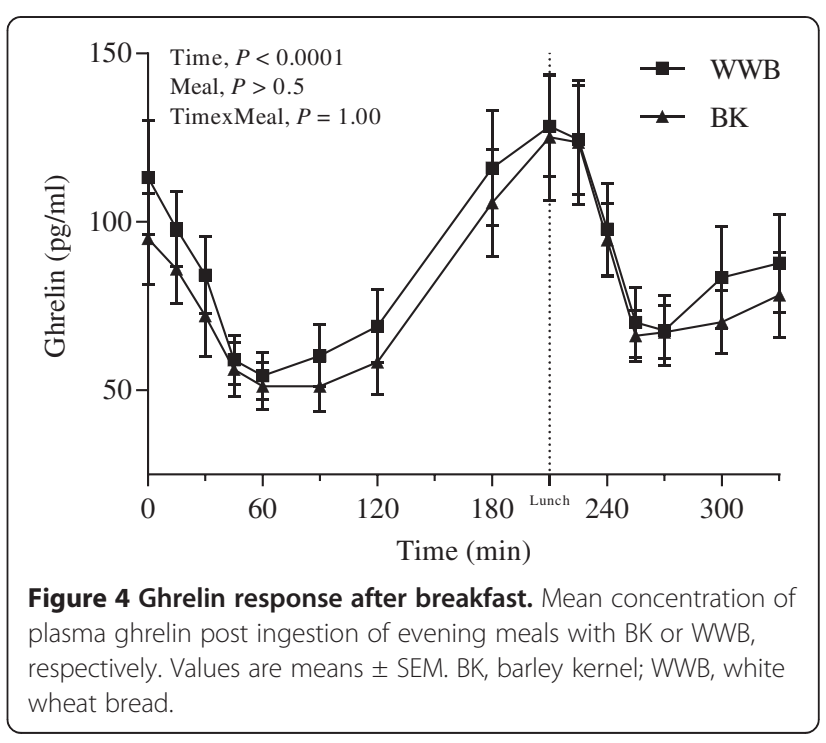




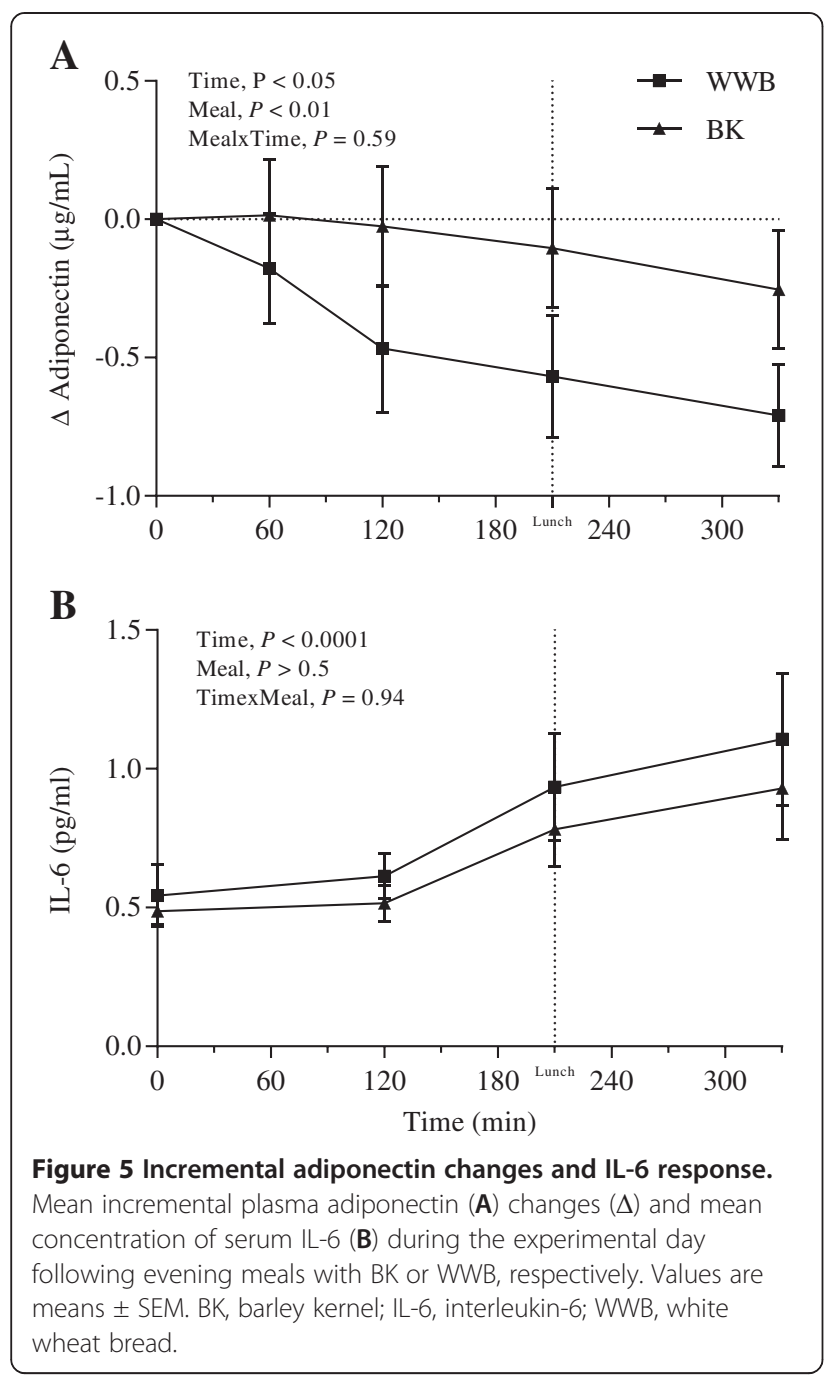

inulin, possible mediated through the formation of SCFA [42]. It can be suggested that the effects on gastro-intestinal hormones seen in the present study after the BK evening meal, stem from colonic fermentation of indigestible DF in the BK. GLP-1 and GIP, are known to exert insulinotropic effects [43] and have been suggested to account for up to $70 \%$ of meal induced insulin release in humans [44]. Noticeably, the lowered glycaemia and increased incretin concentrations observed during the experimental day after BK evening meal were not accompanied by increased insulin response. However, GLP-1 has previously been reported to improve insulin sensitivity in T2D [45], a phenomenon that might have contributed to the facilitated glucose regulation during the experimental day in the present study in healthy subjects. Another factor that might have contributed to an improved insulin sensitivity after the BK evening meal is reduced f-FFA concentrations compared to the evening WWB reference meal [46]. Belfort et al. (2005) showed that even a modest increase in plasma FFA, well within the physiological range, causes a dose-dependent inhibition of insulin-stimulated glucose disposal and insulin signaling in healthy lean subjects [47].

In the present study, f-IL-6 concentrations tended to be decreased $(P=0.06)$ after the BK evening meals, which is in accordance with previous studies [23,36]. Low-grade chronic systemic inflammation is associated with obesity and insulin resistance [48]. Anti-inflammatory properties of specific indigestible carbohydrates, as present in e.g. BK, might constitute a promising approach aiming at dietary prevention and/or treatment of obesity and the

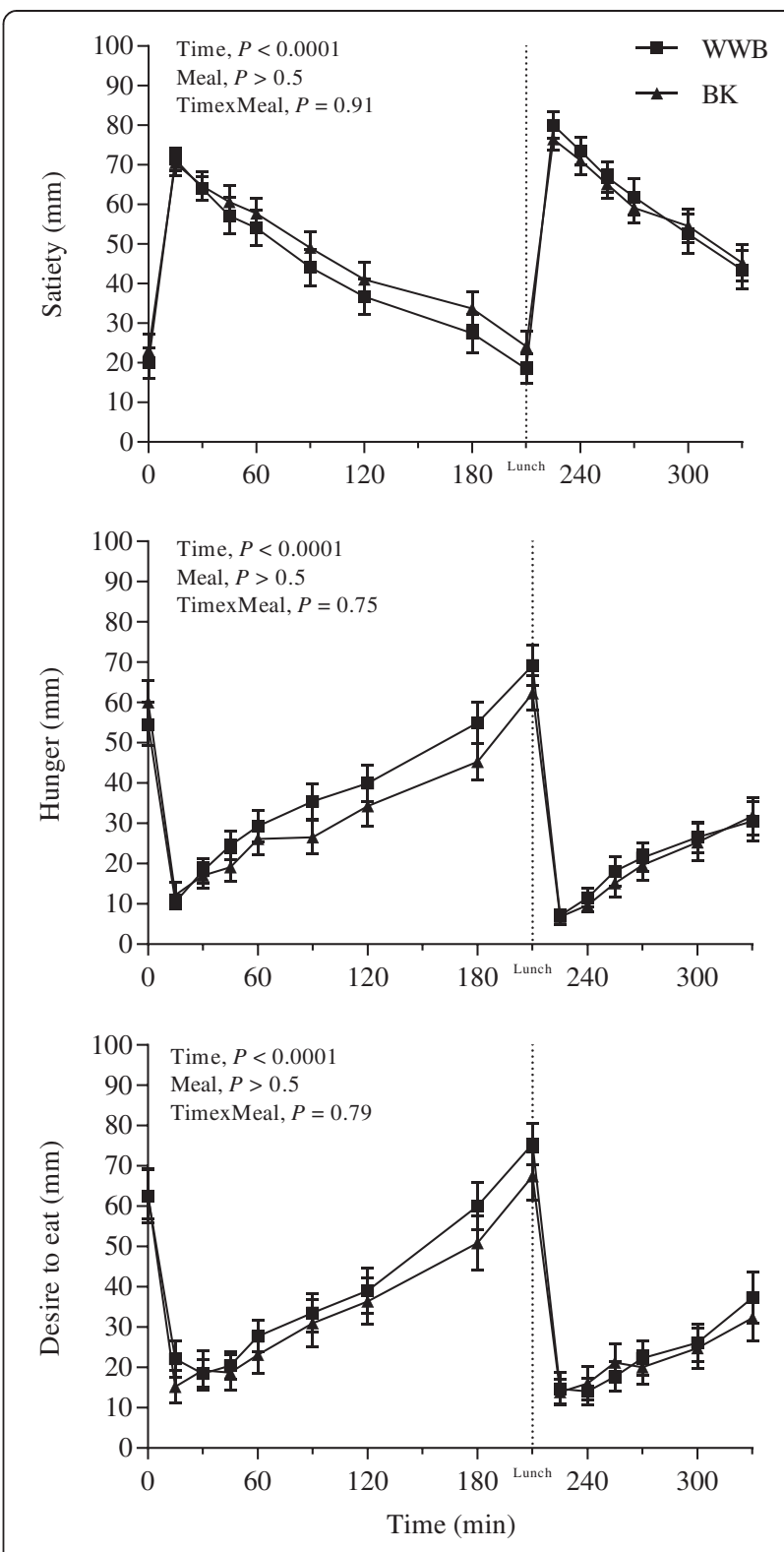

Figure 6 Post-prandial responses of satiety, hunger and desire to eat. Mean subjective ratings of appetite (VAS) during $5.5 \mathrm{~h}$ after breakfast and lunch, following an evening meal of BK or WWB, respectively. Values are means \pm SEM. BK, barley kernel; WWB, white wheat bread. 
metabolic syndrome. In a cross-sectional study by Yannakoulia et al. (2008), consumption of WG cereals and low-fat dairy products were positively associated with adiponectin concentrations among healthy women [49]. The authors suggested that adiponectin may be a mediator of the decreased risk of T2D associated with higher WG intake. Adiponectin has been shown to possess not only insulin sensitizing properties but also to have antiinflammatory effects [50]. Decreased concentrations of adiponectin are observed in obesity and T2D [51,52]. In the present study, we show that BK evening meal resulted in maintained adiponectin concentrations in the postprandial period after breakfast as compared to the decrease observed after WWB evening meal. The metabolic relevance of this finding remains to be elucidated. However, adiponectin concentrations in subjects with metabolic disorders show a more pronounced decrease in the post-prandial phase compared to healthy subjects $[53,54]$.

\section{Conclusions}

The results indicate that indigestible carbohydrates, as present in BK, have the potential to facilitate glucose regulation in healthy subjects in a time period of 10.5-16 $\mathrm{h}$, decrease inflammatory markers, decrease FFA, decrease hunger sensations and reduce energy intake at a subsequent lunch. Interestingly, the BK evening meal resulted in an increased release of GLP-1 during the whole experimental period. The effects are suggested to be mediated through gut microbial fermentation, proposing a role of gut microbiota in modulating host metabolism in humans. Colonic fermentation of specific indigestible carbohydrates may provide one possible mechanism by which WG have proven beneficial in prevention of obesity and T2D. Taken together, the beneficial effects of BK are supportive for a prebiotic potential of intrinsic indigestible carbohydrates in barley kernel based products.

\section{Abbreviations}

AUC: Area under curve; BK: Barley kernel; BMI: Body mass index; DF: Dietary fibre; f-: Fasting-; GIP: Glucose-dependent insulinotropic polypeptide; GLP-1: Glucagon-like peptide-1; GP²: Glucose profile; $\mathrm{H}_{2}$ : Breath hydrogen; iAUC: Incremental area under curve; IL-6: Interleukin-6; iPeak: Incremental peak; MetS: Metabolic syndrome; PYY: Peptide YY; RS: Resistant starch; SCFA: Short chain fatty acids; T2D: Type 2 diabetes; VAS: Visual analogue scale; WG: Whole grain; WWB: White wheat bread.
}

\section{Competing interests}

The authors declare that they have no competing interests.

\section{Authors' contributions}

ACN, EMÖ, and IMEB designed the research; EVJ, ACN, EMÖ, and IMEB supervised and/or conducted the research; EVJ analyzed data and performed statistical analysis; EVJ, ACN, EMÖ, and IMEB wrote the paper; and ACN, EMÖ and IMEB had primary responsibility for the final content. All authors have read and approved the final manuscript.

\section{Acknowledgment}

This study was funded by the Lund University Antidiabetic Food Center, a VINNOVA VINN Excellence Center.

Received: 22 October 2012 Accepted: 26 March 2013

Published: 11 April 2013

\section{References}

1. Alberti KGMM, Zimmet P, Shaw J: Metabolic syndrome-a new worldwide definition. A Consensus Statement from the International Diabetes Federation. Diabet Med 2006, 23:469-480.

2. Diabetes Fact sheet No312. [http://www.who.int/mediacentre/factsheets/ fs312/en/index.html]

3. O'Neil CE, Zanovec M, Cho SS, Nicklas TA: Whole grain and fiber consumption are associated with lower body weight measures in US adults: National Health and Nutrition Examination Survey 1999-2004. Nutr Res 2010, 30:815-822.

4. Good CK, Holschuh N, Albertson AM, Eldridge AL: Whole Grain Consumption and Body Mass Index in Adult Women: An Analysis of NHANES 1999-2000 and the USDA Pyramid Servings Database. J Am Coll Nutr 2008, 27:80-87.

5. Harland II, Garton LE: Whole-grain intake as a marker of healthy body weight and adiposity. Public Health Nutr 2008, 11:554-563.

6. McKeown NM, Meigs JB, Liu S, Wilson PW, Jacques PF: Whole-grain intake is favorably associated with metabolic risk factors for type 2 diabetes and cardiovascular disease in the Framingham Offspring Study. Am J Clin Nutr 2002, 76:390-398.

7. Schulze MB, Schulz M, Heidemann C, Schienkiewitz A, Hoffmann K, Boeing $\mathrm{H}$ : Fiber and Magnesium Intake and Incidence of Type 2 Diabetes: A Prospective Study and Meta-analysis. Arch Intern Med 2007, 167:956-965.

8. Park Y, Subar AF, Hollenbeck A, Schatzkin A: Dietary Fiber Intake and Mortality in the NIH-AARP Diet and Health Study. Arch Intern Med 2011, 171:1061-1068.

9. Gemen R, de Vries JF, Slavin JL: Relationship between molecular structure of cereal dietary fiber and health effects: focus on glucose/insulin response and gut health. Nutr Rev 2011, 69:22-33.

10. Slavin J: Whole grains and human health. Nutr Res Rev 2004, 17:99-110.

11. Björck IME, Granfeldt YE, Liljeberg HGM, Tovar J, Asp N-G: Food properties affecting the digestion and absorption of carbohydrates. Am J Clin Nutr 1994, 59(suppl):699S-705S.

12. Björck I, Östman E, Kristensen M, Mateo Anson N, Price RK, Haenen GRMM, Havenaar R, Bach Knudsen KE, Frid A, Mykkänen H, et al: Cereal grains for nutrition and health benefits: Overview of results from in vitro, animal and human studies in the HEALTHGRAIN project. Trends in Food Science \& Technology 2012, 25:87-100.

13. Ley RE, Hamady M, Lozupone C, Turnbaugh PJ, Ramey RR, Bircher JS, Schlegel ML, Tucker TA, Schrenzel MD, Knight R, Gordon J: Evolution of Mammals and Their Gut Microbes. Science 2008, 320:1647-1651.

14. Flint HJ: The impact of nutrition on the human microbiome. Nutr Rev 2012, 70:S10-S13.

15. Round JL, Mazmanian SK: The gut microbiota shapes intestinal immune responses during health and disease. Nat Rev Immunol 2009, 9:313-323.

16. Vijay-Kumar M, Aitken JD, Carvalho FA, Cullender TC, Mwangi S, Srinivasan S, Sitaraman SV, Knight R, Ley RE, Gewirtz AT: Metabolic Syndrome and Altered Gut Microbiota in Mice Lacking Toll-Like Receptor 5. Science 2010, 328:228-231.

17. Harte AL, Varma MC, Tripathi G, McGee KC, Al-Daghri NM, Al-Attas OS, Sabico S, O'Hare JP, Ceriello A, Saravanan P, et al: High Fat Intake Leads to Acute Postprandial Exposure to Circulating Endotoxin in Type 2 Diabetic Subjects. Diabetes Care 2012, 35:375-382.

18. Erridge C, Attina T, Spickett CM, Webb DJ: A high-fat meal induces lowgrade endotoxemia: evidence of a novel mechanism of postprandial inflammation. Am J Clin Nutr 2007, 86:1286-1292.

19. Cani PD, Possemiers S, Van de Wiele T, Guiot Y, Everard A, Rottier O, Geurts L, Naslain D, Neyrinck A, Lambert DM, et al: Changes in gut microbiota control inflammation in obese mice through a mechanism involving GLP-2-driven improvement of gut permeability. Gut 2009, 58:1091-1103.

20. Everard A, Lazarevic V, Derrien M, Girard M, Muccioli GG, Neyrinck AM, Possemiers S, Van Holle A, François P, de Vos WM, et al: Responses of Gut Microbiota and Glucose and Lipid Metabolism to Prebiotics in Genetic 
Obese and Diet-Induced Leptin-Resistant Mice. Diabetes 2011, 60:2775-2786.

21. Cani P, Neyrinck A, Fava F, Knauf C, Burcelin R, Tuohy K, Gibson G, Delzenne $\mathrm{N}$ : Selective increases of bifidobacteria in gut microflora improve highfat-diet-induced diabetes in mice through a mechanism associated with endotoxaemia. Diabetologia 2007, 50:2374-2383.

22. Lutsey PL, Jacobs DR, Kori S, Mayer-Davis E, Shea S, Steffen LM, Szklo M, Tracy R: Whole grain intake and its cross-sectional association with obesity, insulin resistance, inflammation, diabetes and subclinical CVD: The MESA Study. Br J Nutr 2007, 98:397-405.

23. Nilsson AC, Ostman EM, Holst JJ, Bjorck IM: Including indigestible carbohydrates in the evening meal of healthy subjects improves glucose tolerance, lowers inflammatory markers, and increases satiety after a subsequent standardized breakfast. J Nutr 2008, 138:732-739.

24. Thorburn A, Muir J, Proietto J: Carbohydrate fermentation decreases hepatic glucose output in healthy subjects. Metabolism 1993, 42:780-785.

25. Nilsson AC, Ostman EM, Granfeldt Y, Bjorck IM: Effect of cereal test breakfasts differing in glycemic index and content of indigestible carbohydrates on daylong glucose tolerance in healthy subjects. Am J Clin Nutr 2008, 87:645-654.

26. Nilsson A, Ostman E, Preston T, Bjorck I: Effects of GI vs content of cereal fibre of the evening meal on glucose tolerance at a subsequent standardized breakfast. Eur J Clin Nutr 2008, 62:712-720.

27. Torekov SS, Madsbad S, Holst JJ: Obesity - an indication for GLP-1 treatment? Obesity pathophysiology and GLP-1 treatment potential. Obes Rev 2011, 12:593-601.

28. Cani PD, Lecourt E, Dewulf EM, Sohet FM, Pachikian BD, Naslain D, De Backer F, Neyrinck AM, Delzenne NM: Gut microbiota fermentation of prebiotics increases satietogenic and incretin gut peptide production with consequences for appetite sensation and glucose response after a meal. Am J Clin Nutr 2009, 90:1236-1243.

29. Aaboe K, Krarup T, Madsbad S, Holst JJ: GLP-1: physiological effects and potential therapeutic applications. Diabetes, Obesity and Metabolism 2008, 10:994-1003.

30. Björck IME, Siljeström MA: In-vivo and in-vitro digestability of starch in autoclaved pea and potatoe products. J Sci Food Agric 1992, 58:541-553.

31. Holm J, Björck IME, Drews A, Asp N-G: A rapid method for the analysis of starch. Starch/Stärke 1986, 38:224-226.

32. Åkerberg AK, Liljeberg HG, Granfeldt YE, Drews AW, Björck IM: An in vitro method, based on chewing, to predict resistant starch content in foods allows parallel determination of potentially available starch and dietary fiber. J Nutr 1998, 128:651-660.

33. Asp N-G, Johansson C-G, Hallmer H, Siljeström M: Rapid enzymatic assay of insoluble and soluble dietary fiber. J Agric Food Chem 1983, 31:476-482.

34. Rosén LAH, Östman EM, Björck IME: Postprandial Glycemia, Insulinemia, and Satiety Responses in Healthy Subjects after Whole Grain Rye Bread Made from Different Rye Varieties. 2. J Agric Food Chem 2011, 59:12149-12154.

35. Wolever TMS, Jenkins DJA, Ocana AM, Rao VA, Collier GR: Second-meal effect: low-glycemic-index foods eaten at dinner improve subsequent breakfast glycemic response. Am J Clin Nutr 1988, 48:1041-1047.

36. Priebe MG, Wang H, Weening D, Schepers $M$, Preston $T$, Vonk RJ: Factors related to colonic fermentation of nondigestible carbohydrates of a previous evening meal increase tissue glucose uptake and moderate glucose-associated inflammation. Am J Clin Nutr 2010, 91:90-97.

37. Cani PD, Hoste S, Guiot Y, Delzenne NM: Dietary non-digestible carbohydrates promote L-cell differentiation in the proximal colon of rats. Br J Nutr 2007, 98:32-37.

38. Tolhurst G, Heffron H, Lam YS, Parker HE, Habib AM, Diakogiannaki E, Cameron J, Grosse J, Reimann F, Gribble FM: Short-chain fatty acids stimulate glucagon-like peptide-1 secretion via the G-protein-coupled receptor FFAR2. Diabetes 2012, 61:364-371.

39. Flint A, Raben A, Astrup A, Holst JJ: Glucagon-like Peptide 1 Promotes Satiety and Suppresses Energy Intake in Humans. J Clin Invest 1998, 101:515-520.

40. Verdich C, Flint A, Gutzwiller J-P, Naslund E, Beglinger C, Hellstrom PM, Long SJ, Morgan LM, Holst JJ, Astrup A: A Meta-Analysis of the Effect of Glucagon-Like Peptide-1 (7-36) Amide on Ad Libitum Energy Intake in Humans. J Clin Endocrinol Metab 2001, 86:4382-4389.
41. Wren AM, Seal LJ, Cohen MA, Brynes AE, Frost GS, Murphy KG, Dhillo WS Ghatei MA, Bloom SR: Ghrelin enhances appetite and increases food intake in humans. J Clin Endocrinol Metab 2001, 86:5992

42. Tarini J, Wolever TMS: The fermentable fibre inulin increases postprandial serum short-chain fatty acids and reduces free-fatty acids and ghrelin in healthy subjects. Applied Physiology, Nutrition \& Metabolism 2010, 35:9-16.

43. Holst JJ, Deacon CF, Vilsboll T, Krarup T, Madsbad S: Glucagon-like peptide-1, glucose homeostasis and diabetes. Trends Mol Med 2008, 14:161-168

44. Asmar M: New physiological effects of the incretin hormones GLP-1 and GIP. Dan Med Bull 2011, 58:B4248.

45. Zander M, Madsbad S, Madsen JL, Holst JJ: Effect of 6-week course of glucagon-like peptide 1 on glycaemic control, insulin sensitivity, and beta-cell function in type 2 diabetes: a parallel-group study. Lancet 2002, 359:824-830.

46. Robertson MD: Metabolic cross talk between the colon and the periphery: implications for insulin sensitivity. Proc Nutr Soc 2007, 66:351-361.

47. Belfort R, Mandarino L, Kashyap S, Wirfel K, Pratipanawatr T, Berria R, DeFronzo RA, Cusi K: Dose-response Effect of Elevated Plasma Free Fatty Acid on Insulin Signaling. Diabetes 2005, 54:1640-1648.

48. Wellen KE, Hotamisligil GS: Inflammation, stress, and diabetes. J Clin Invest 2005, 115:1111-1119.

49. Yannakoulia M, Yiannakouris N, Melistas L, Kontogianni MD, Malagaris I, Mantzoros CS: A dietary pattern characterized by high consumption of whole-grain cereals and low-fat dairy products and low consumption of refined cereals is positively associated with plasma adiponectin levels in healthy women. Metabolism 2008, 57:824-830.

50. Vaiopoulos AG, Marinou K, Christodoulides C, Koutsilieris M: The role of adiponectin in human vascular physiology. Int J Cardiol 2012, 155:188-193.

51. Weyer C, Funahashi T, Tanaka S, Hotta K, Matsuzawa Y, Pratley RE, Tataranni PA: Hypoadiponectinemia in Obesity and Type 2 Diabetes: Close Association with Insulin Resistance and Hyperinsulinemia. J Clin Endocrinol Metab 2001, 86:1930-1935

52. Lihn AS, Pedersen SB, Richelsen B: Adiponectin: action, regulation and association to insulin sensitivity. Obesity Reviews 2005, 6:13-21.

53. Carlson J, Turpin A, Wiebke G, Hunt S, Adams T: Pre- and post- prandial appetite hormone levels in normal weight and severely obese women. Nutr Metab 2009, 6:32

54. English PJ, Coughlin SR, Hayden K, Malik IA, Wilding JPH: Plasma Adiponectin Increases Postprandially in Obese, but not in Lean, Subjects. Obesity 2003, 11:839-844.

\section{doi:10.1186/1475-2891-12-46}

Cite this article as: Johansson et al:: Effects of indigestible carbohydrates in barley on glucose metabolism, appetite and voluntary food intake over 16 h in healthy adults. Nutrition Journal 2013 12:46.

\section{Submit your next manuscript to BioMed Central and take full advantage of:}

- Convenient online submission

- Thorough peer review

- No space constraints or color figure charges

- Immediate publication on acceptance

- Inclusion in PubMed, CAS, Scopus and Google Scholar

- Research which is freely available for redistribution 